\title{
An Energy Investigation of An Organic Rankine Cycle Utilizing Three Organic Fluids
}

\author{
Rabah Touaibi' (D) Hasan Koten ${ }^{2}$ (D) Ozlem Boydak ${ }^{2}$ (D) \\ ${ }^{1}$ Djilali Bounaama University, Laboratory of FIMA, Khemis Miliana, Algeria \\ ${ }^{2}$ Istanbul Medeniyet University, Department of Mechanical Engineering, Istanbul, Turkey
}

A B S T R ACT
Tis study presents an energy study of an Organic Rankine Cycle (ORC) by comparing
three organic fluids. The latter is considered as a promising cycle for the conversion of
heat into mechanical energy adapted to low-temperature heat sources; it uses more volatile
organic fluids than water, which generally has high molecular weights, thus allowing operat-
ing pressures at temperatures lower than those of the traditional Rankine cycle. This study
devoted to the energy analysis of the ORC cycle, taking into account the effect of the operat-
ing temperatures and the choice of the organic fluid on the cycle performance. The utilized
three fluids were Toluene, R245fa and R123. The results obtained show that the Toluene
organic fluid has the best energy efficiency of the cycle with $7.45 \%$.

\author{
Article History: \\ Received: 2019/11/28 \\ Accepted: 2020/01/31 \\ Online: $2020 / 03 / 26$ \\ Correspondence to: Rabah Touaibi, \\ Laboratory of FIMA, Djilali \\ Bounaama University, Khemis \\ Miliana, Algeria \\ E-Mail:ra.touaibi@gmail.com
}

Keywords:

ORC cycle, Energy Analysis, Organic Fluids, Performance, Toluene

\section{INTRODUCTION}

Crurr urrently, a continuous increase in energy consumption is noted which has led to environmental problems such as global warming and the depletion of fossil fuels. Total global energy consumption increased from 575 quadrillion British thermal units (BTUs) in 2015 to 736 quadruplets in 2040, with an increase of 28\% [1]. Organic Rankine Cycle is one of the most commonly utilized technologies for producing electricity from low-grade heat [2], which can be derived from Geothermal [3,5], Biomass [6,7], Industrial waste [8] and solar energy $[9,10]$. The organic fluids used by organic Rankine rings are usually: hydrofluorocarbon refrigerants, ammonia, butane, isopentane, toluene depending on the nature of the fluid, isentropic expansion from the dew curve may conserve, decrease, or increase the vapor titer. It is, in fact, the slope of the dew curve in the Mollier diagram that explains this phenomenon specific to the nature of the fluid. The aim of this study is to estimate the mechanical power that can be provided by an organic rankine cycle by studying the effect of the evaporation temperature and the choice of the organic fluid adapted to this type of energy conversion system and to find the organic rankine cycle performance by comparing three different organic fluids; Toluene, R245fa and R123.

\section{DESCRIPTION OF THE ORC CYCLE}

The heat transfer fluid at high temperature transfers the heat stored to the evaporator of the ORC cycle. This fluid can reach relatively high temperatures. The organic fluid pressurized by the pump is heated, then evaporated and superheated in the evaporator by the heat energy from the heat source, transferred to the latter. The superheated steam obtained at the outlet of the evaporator drives the turbine, which is a rotational movement drives an alternator for the production of electricity. The steam at the outlet of the turbine is directed to the condenser where it is cooled by a flow of cooling water.

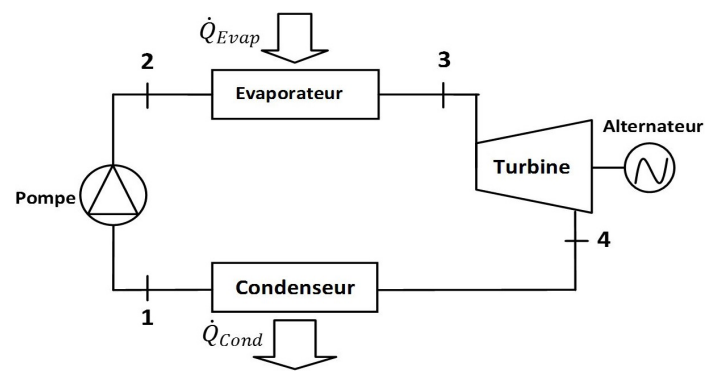

Figure 1. Scheme of Organic Rankine Cycle (ORC)

\section{THERMODYNAMIC MODEL}

The ORC cycle is analyzed by applying the principle of conservation of mass and energy according to the first law of thermodynamics, for each of the four 
components of the organic Rankine cycle, taking the following hypotheses:

Changes in kinetic energy and potential energy are negligible.

The system is adiabatic (without thermal losses).

The system operates at steady-state.

\section{Mass and Energy Balance of the ORC Cycle}

The input and output mass flows are equal in steady state, we have:

$$
\dot{\mathrm{m}}_{1}=\dot{\mathrm{m}}_{2}=\dot{\mathrm{m}}_{3}=\dot{\mathrm{m}}_{4}=\dot{\mathrm{m}}
$$

\section{Pump}

The circulation pump allows the movement of the organic fluid from the low pressure condenser to the evaporator at high pressure, it is possible to determine the consumption of the pump. The energy balance of the pump is written as follows:

$$
\dot{\mathrm{W}}_{\mathrm{P}}=\dot{\mathrm{m}}\left(\mathrm{h}_{2}-\mathrm{h}_{1}\right)
$$

The specific work consumed by the pump to compress the fluid is written:

$$
\mathcal{W}_{\mathrm{P}}=\left(\mathrm{h}_{2}-\mathrm{h}_{1}\right)=v\left(\mathrm{P}_{2}-\mathrm{P}_{1}\right)
$$

For an irreversible adiabatic compression, the mechanical efficiency of the pump is introduced as follows:

$$
\eta_{\text {Pis }}=\frac{\dot{\mathrm{W}}_{\text {P rév }}}{\dot{\mathrm{W}}_{\text {P irrév }}}=\frac{\dot{\mathrm{W}}_{\mathrm{P} \text { is }}}{\dot{\mathrm{W}}_{\mathrm{P}}}=\frac{\left(\mathrm{h}_{2 \text { is }}-\mathrm{h}_{1}\right)}{\left(\mathrm{h}_{2}-\mathrm{h}_{1}\right)}
$$

\section{Evaporator}

The working fluid enters the evaporator in the liquid state and heated therein at constant pressure P2 to the evaporation temperature, then it evaporates at constant temperature and pressure. The energy balance of the evaporator is written as follows:

$$
\dot{\mathrm{Q}}_{\text {Evap }}=\dot{\mathrm{m}}\left(\mathrm{h}_{3}-\mathrm{h}_{2}\right)
$$

\section{Turbine}

The expansion in the turbine is considered adiabatic and irreversible with a constant isentropic efficiency which is defined as follows:

$$
\eta_{\mathrm{T} \text { is }}=\frac{\dot{\mathrm{W}}_{\mathrm{T} \text { irrév }}}{\dot{\mathrm{W}}_{\mathrm{T} \text { rév }}}=\frac{\dot{\mathrm{W}}_{\mathrm{T}}}{\dot{\mathrm{W}}_{\mathrm{T} \text { is }}}=\frac{\left(\mathrm{h}_{3}-\mathrm{h}_{4}\right)}{\left(\mathrm{h}_{3}-\mathrm{h}_{4}\right)}
$$

The energy balance of the turbine is written as follows:

$$
\dot{\mathrm{W}}_{\mathrm{T}}=\dot{\mathrm{m}}\left(\mathrm{h}_{3}-\mathrm{h}_{4}\right)=\dot{\mathrm{m}}\left(\mathrm{h}_{3}-\mathrm{h}_{4 \text { is }}\right) \eta_{\mathrm{T} \text {.méc }}
$$

The electric power of the turbine is given by:

$$
\dot{W}_{\text {T.ORC }}^{\text {elec }}=\eta_{\text {gen }}{ }^{*} \dot{W}_{\text {T.ORC }}
$$

\section{Condenser}

The working fluid enters the condenser in the vapor state, condenses at constant temperature and pressure, and exits in the liquid state where it yields a quantity of heat. The energy balance of the condenser is written as follows:

$$
\dot{\mathrm{Q}}_{\text {Cond }}=\dot{\mathrm{m}}\left(\mathrm{h}_{4}-\mathrm{h}_{1}\right)
$$

\section{Performances of the ORC System}

The thermal efficiency of organic Rankine cycle is defined as:

$$
\begin{aligned}
& \eta_{\mathrm{Th}}=\frac{\dot{\mathrm{W}}_{\text {net.ORC }}}{\dot{\mathrm{Q}}_{\text {Evp.ORC }}} \\
& \dot{\mathrm{W}}_{\text {net.ORC }}=\dot{\mathrm{W}}_{\mathrm{T}}-\dot{\mathrm{W}}_{\mathrm{P}}
\end{aligned}
$$

\section{RESULTS}

In this part we compared the thermodynamic behavior of three types of organic fluids R245fa, R123 and toluene. The input parameters of the organic Rankine cycle operation are as follows: $\mathrm{T}_{\text {Evap }}=100{ }^{\circ} \mathrm{C} ; \mathrm{T}_{\text {Cond }}=40{ }^{\circ} \mathrm{C} ; \dot{\mathrm{m}}=1 \mathrm{~kg} / \mathrm{s}$. The thermo-physical characteristics of the working fluids of the various points of the cycle are calculated by the Solkane and Coolpack software [11]. Table 1 represents the thermodynamic characteristics of the various points of the ORC cycle for the three working fluids.

In order to jointly consider the fluid having the highest net mechanical power, and the best energy efficiency. This study allowed us to compare the behavior of different types of working fluid under similar conditions. The thermodynamic performances of the ORC cycle of the three fluids are shown in Table 2.

The results show that the Toluene organic fluid appears to be a good compromise for these two criteria, it is the fluid 
Table 1. Characteristic thermodynamic points of ORC cycle

$\mathrm{T}\left[{ }^{\circ} \mathrm{C}\right] \quad \mathrm{P}[\mathrm{bar}] \quad \mathrm{h}[\mathrm{kJ} / \mathrm{kg}] \quad \mathrm{s}[\mathrm{kJ} / \mathrm{kg} \cdot \mathrm{K}] \quad \mathrm{x}[-]$

Working fluid: Toluene

\begin{tabular}{cccccr}
1 & 40 & 0.07907 & -132.3 & -0.3799 & 0 \\
2 & 40.02 & 0.7475 & -132.3 & -0.3799 & 1 \\
3 & 100 & 0.475 & 347.1 & 0.9306 & 1 \\
4 & 45.37 & 0.07907 & 278.1 & 0.9306 & 1 \\
& \multicolumn{5}{c}{ Working fluid: R123 } \\
1 & 40 & 1.547 & 241.9 & 1.142 & 0 \\
2 & 40.25 & 7.868 & 242.3 & 1.142 & 1 \\
3 & 100 & 7.868 & 442.5 & 1.694 & 1 \\
4 & 50.08 & 1.547 & 414.6 & 1.694 & 1 \\
& & Working fluid: R245fa & & \\
1 & 40 & 2.496 & 252.6 & 1.179 & 0 \\
2 & 40.4 & 12.69 & 253.4 & 1.179 & 1 \\
3 & 100 & 12.69 & 474.1 & 1.791 & 1 \\
4 & 50.44 & 2.496 & 444.2 & 1.791 & 1
\end{tabular}

Table 2. Thermodynamic performances of the ORC cycle

\begin{tabular}{cccc}
\hline & \multicolumn{3}{c}{ Working fluids } \\
$\dot{\mathrm{W}}_{\text {Pump }}(\mathrm{kW})$ & 0.1089 & 0.4445 & $\mathrm{R} 123$ \\
$\dot{\mathrm{Q}}_{\text {Evp }}(\mathrm{kW})$ & 479.4 & 200.1 & 0.7853 \\
$\dot{\mathrm{W}}_{\text {Turbine }}(\mathrm{kW})$ & 69 & 27.82 & 220.8 \\
$\dot{\mathrm{Q}}_{\text {Cond }}(\mathrm{kW})$ & 410.5 & 172.7 & 29.91 \\
$\dot{\mathrm{W}}_{\text {net.ORC }}$ & 68.92 & 27.38 & 191.7 \\
$\eta_{\text {th.ORC }}(\%)$ & 14.38 & 13.68 & 29.12 \\
& & & 13.19
\end{tabular}

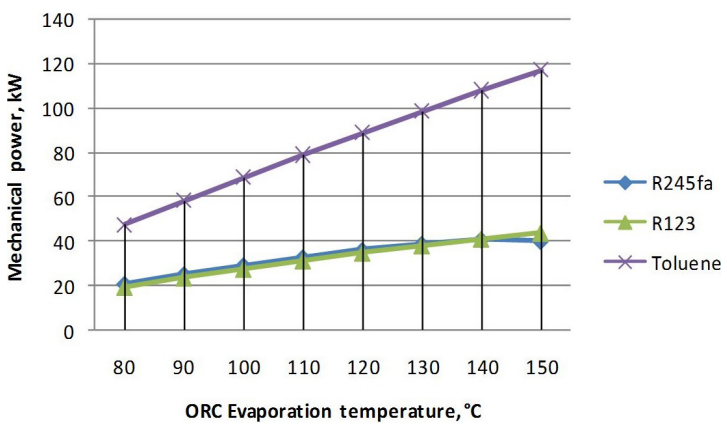

Figure 2. Variation of mechanical power of Turbine with ORC evaporation temperature according to the studied working fluids

that has the highest value of the net mechanical power $\dot{\mathrm{W}}_{\text {net. ORC }}=68.92 \mathrm{~kW}$ compared with the other fluids, it is also a fluid which presents the best energetic efficiency of the cycle which equals c $_{\text {ORC_Toluene }}=14.38 \%$ compared to that of the organic fluid R123 $\varsigma_{\text {ORC R123 }}=13.68 \%$ and that of the organic fluid $\varsigma_{\text {ORC_R } 245 \mathrm{fa}}=13.19 \%$

\section{Parametric Study}

In this part, we studied the influence of the evaporation temperature of the ORC cycle on the performances of the organic Rankine cycle, namely the net power delivered by the ORC cycle and the cycle efficiency using the three organic fluids. To do this by keeping the condensing temperature constant, that is to say by fixing the condensation temperature $\left(\mathrm{T}_{\text {Cond }}=40^{\circ} \mathrm{C}\right)$, and by varying the evaporation temperature in the range of $\left[80{ }^{\circ} \mathrm{C}-150{ }^{\circ} \mathrm{C}\right]$. Fig. 2 shows the effect of the evaporation temperature on the net mechanical power provided by the ORC cycle for the three organic fluids used. The results show that the mechanical power supplied increases with the increase of the evaporation temperature for the three fluids. The Toluene fluid gives a very high mechanical power relative to the other fluids.

Fig. 3 shows the effect of the evaporation temperature on the thermal power received by the evaporator to feed the organic Rankine cycle. The results show that the thermal power required for the supply of the ORC cycle is increased with the increase of the evaporation temperature, the working fluid Toluene uses a lot of energy during its vaporization at the evaporator.

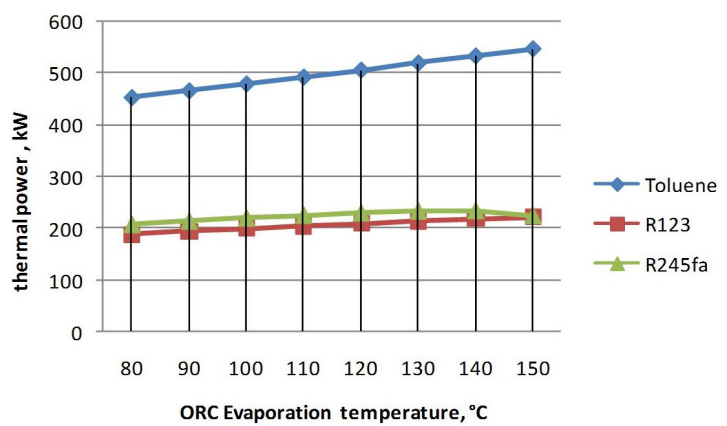

Figure 3. Variation of thermal power of evaporator with ORC evaporation temperature according to the studied working fluids

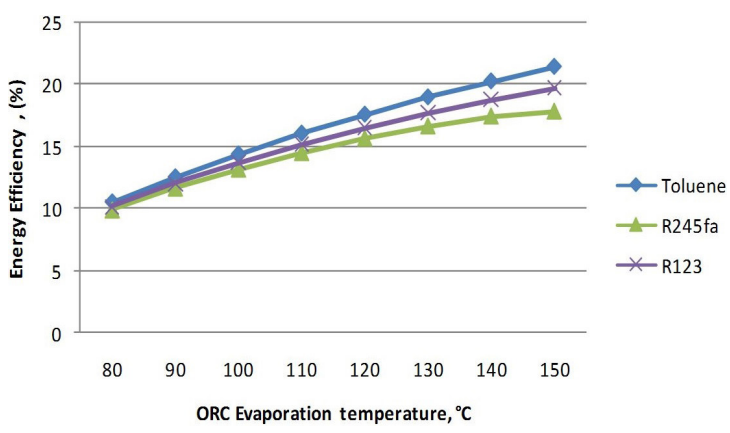

Figure 4. Variation of Energy Efficiency with ORC evaporation temperature according to the studied working fluids

\section{CONCLUSION}

This work focused on the energy study of an Organic Rankine Cycle (ORC) for the production of electrical energy, based on the use of an organic fluid. The parametric study of the organic Rankine cycle has made it possible 
to select the best organic fluid with good thermodynamic performance, which is the Toluene which is the fluid with the highest value of the net mechanical power and a yield of high compared to other fluids. On the other hand, we have been able to analyze and highlight the influence of the evaporation temperature and to find that the cycle efficiency increases significantly with the increase of the evaporation temperature especially for the Toluene fluid where the efficiency energy increase from $10.5 \%$ to 21.45 $\%$ over a temperature range of $80^{\circ} \mathrm{C}-150{ }^{\circ} \mathrm{C}$.

\section{REFERENCES}

1. Energy Information Administration (2017). International energyoutlook, USA: Accessed from "https://www.eia.gov/ outlooks/ieo/\#1".

2. Braimakis, K., \&Karellas, S. (2018). Energetic optimization of regenerative Organic Rankine Cycle (ORC) configurations. Energy Conversion and Management, 159, 353-370.

3. Heberle, F., \&Brüggemann, D. (2010). Exergy based fluid selection for a geothermal Organic Rankine Cycle for combined heat and power generation. Applied Thermal Engineering, 30(11-12), 1326 1332.
4. Liu, Q., Duan, Y., \& Yang, Z. (2013). Performance analyses of geothermal organic Rankine cycles with selected hydrocarbon working fluids. Energy, 63, 123-132.

5. Bu, X., Wang, L., \& Li, H. (2013). Performance analysis and working fluid selection for geothermal energy-powered organic Rankinevapor compression air conditioning. Geothermal Energy, 1(1), 2.

6. Drescher, U., \&Brüggemann, D. (2007). Fluid selection for the Organic Rankine Cycle (ORC) in biomass power and heat plants. Applied thermal engineering, 27(1), 223-228.

7. Taljan, G., Verbič, G., Pantoš, M., Sakulin, M., \&Fickert, L. (2012). Optimal sizing of biomass-fired Organic Rankine Cycle CHP system with heat storage. RenewableEnergy, 41, 29-38.

8. Sun, W., Yue, X., \& Wang, Y. (2017). Exergy efficiency analysis of ORC (Organic Rankine Cycle) and ORC-based combined cycles driven by low-temperature waste heat. Energy Conversion and Management, 135, 63-73.

9. Rayegan, R., \& Tao, Y. X. (2011). A procedure to select working fluids for Solar Organic Rankine Cycles (ORCs). RenewableEnergy, 36(2), 659-670.

10. Shaaban, S. (2016). Analysis of an integrated solarc ombined cycle with steam and organic Rankine cycles as bottoming cycles. Energy Conversion and Management, 126, 1003-1012.

11. Solkane 8.0.0, Solvay Special Chemicals. 